\title{
Comparação de mapeamentos do uso da terra por técnicas de geoprocessamento no município de São Lourenço do Sul/RS
}

\begin{abstract}
A erosão é um processo que ocorre naturalmente no planeta, resultado da modificação constante do relevo. Esse processo, entretanto, tem sido acelerado por conta de usos inadequados das capacidades de cada solo; bem como a retirada de sua cobertura vegetal protetora. A consequência dessa aceleração, geralmente, é percebida na intensificação de desastres naturais, como inundações e deslizamentos. Atualmente o estudo para controle de erosão é caro e demanda tempo. Logo, as técnicas de geoprocessamento vêm como forma de agilizar as análises, poupando tempo e barateando o processo (sem perder a qualidade). 0 objetivo do trabalho foi analisar dois mapeamentos distintos de uso da terra, e comparar as possíveis incompatibilidades entre eles, indicando provável impacto ambiental decorrente de uso. Através da comparação, fica evidente que alguns solos que são suscetíveis a erosão e possuem baixa disponibilidade hídrica, como as colinas, estão sendo utilizados para cultivo. Em contrapartida, em menor escala, nota-se que os solos de planícies baixas lagunares não estão sendo utilizado para cultivo, conforme estipulado na capacidade original de uso. Apesar do município de São Lourenço do Sul possuir uma classificação para o seu uso do solo, constatou-se que essa capacidade não caracteriza completamente o cenário real, não havendo cumprimento por parte dos moradores nem fiscalização do poder público quanto a esse uso. É necessário, para que se atinja uma redução do alto grau erosivo no município, a criação de planos e programas que facilitem a identificação da área ideal a ser cultivada, bem como as corretas técnicas de plantio e manejo a serem utilizadas por parte do agricultor. Assim, as perdas de solo serão mitigadas e a conservação da área será restaurada.
\end{abstract}

\section{Comparison of land use mappings by geoprocessing techniques in São Lourenço do Sul/RS}

\begin{abstract}
Erosion is a naturally occurring process on the planet, a result of the constant modification of the relief. This process, however, has been accelerated due to inadequate uses of each individual's capabilities; as well as the removal of your protective vegetable cover. The consequence of this acceleration is generally perceived in the intensification of natural disasters such as floods and landslides. Currently the study for erosion control is expensive and time consuming. Therefore, the techniques of geoprocessing come as a way to streamline analyzes, saving time and cheapening the process (without losing quality). The objective of this work was to analyze two distinct land's use mappings, and to compare possible incompatibilities between them, indicating a probable environmental impact resulting from use. By comparison, it is evident that some soils that are susceptible to erosion and have low water availability, such as the hills being used for cultivation. In contrast, to a lesser extent, it is noted that lowland lagoon soils are not being used for cultivation, as stipulated in the original capacity of use. Although the municipality of São Lourenço do Sul possesses a classification for its use of the soil, it was verified that this capacity does not characterize the real scenario completely, not having complied on the part of the residents nor inspection of the public power regarding this use. It is necessary, in order to achieve a reduction of the high erosive degree in the municipality, the creation of plans and programs that facilitate the identification of the ideal area to be cultivated, as well as the correct techniques of planting and management to be used by the farmer. Therefore, the soil losses will be mitigated and the area conservation will be restored.
\end{abstract}

Keywords: Erosion; Mapping; Geoprocessing.

Topic: Tecnologia, Modelagem e Geoprocessamento

Reviewed anonymously in the process of blind peer.

\section{Mayara Zanchin (iD)}

Universidade Federal de Pelotas, Brasil

http://lattes.cnpq.br/1780472541548130

http://orcid.org/0000-0002-8487-7867

maayfrizzo@gmail.com

\section{Diuliana Leandro (iD}

Universidade Federal de Pelotas, Brasi

http://lattes.cnpq.br/3076528365846421

http://orcid.org/0000-0002-8092-5550

diuliana.leandro@gmail.com

Maurízio Silveira Quadro id

Universidade Federal de Pelotas, Brasil

http://lattes.cnpq.br/1749935262841216

http://orcid.org/0000-0001-8236-7479

mausq@hotmail.com

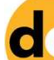

DOI: 10.6008/CBPC2179-6858.2018.005.0028
Received: 10/06/2018

Approved: 24/07/2018

\section{Samanta Tolentino Cecconello (id \\ Universidade Federal de Pelotas, Brasil \\ http://lattes.cnpq.br/0667595394126577 \\ http://orcid.org/0000-0001-5903-6241 \\ satolentino@gmail.com \\ Willian Cézar Nadaleti \\ Universidade Federal de Pelotas, Brasil \\ http://lattes.cnpq.br/4670559561277136 \\ http://orcid.org/0000-0002-4727-4127 \\ williancezarnadaletti@gmail.com \\ Andrea Souza Castro (ID \\ Universidade Federal de Pelotas, Brasil \\ http://lattes.cnpq.br/4328855884811171 \\ http://orcid.org/0000-0003-1989-684X \\ andreacastro@gmail.com}

\section{Referencing this:}

ZANCHIN, M.; LEANDRO, D.; QUADRO, M. S.; CECCONELLO, S. T.; NADALETI, W. C.; CASTRO, A. S.. Comparação de mapeamentos do uso da terra por técnicas de geoprocessamento no município de São Lourenço do Sul/RS. Revista Ibero Americana de Ciências Ambientais, v.9, n.5, p.319-329, 2018. DOI: http://doi.org/10.6008/CВPC21796858.2018 .005 .0028 


\section{INTRODUÇÃO}

A erosão é um processo natural que faz parte da modificação do relevo do planeta e consiste, basicamente, de três etapas: desagregação do solo, transporte de partículas desagregadas e depósito de partículas nas áreas mais baixas (MELO et al., 2008). Entretanto, a erosão tem aumentado devido ao crescimento demográfico desordenado, que resulta em uma utilização dos recursos naturais de forma errônea e irracional esgotando-os. O crescimento populacional demanda maior quantidade de alimentos, promove exploração de áreas inapropriadas e amplia a pressão de uso sobre terras. Muitas vezes, o maior impacto gerado por estas ocupações irregulares está relacionado ao desaparecimento das matas ciliares que circundam os cursos hídricos, bem como o desrespeito frente às áreas de preservação permanente, onde as construções (ou atividades) antrópicas distanciam-se poucos (ou nenhum) metros da água (COSTA et al., 2013).

A diminuição da capacidade produtiva e fertilidade de um solo é uma consequência direta da ação antrópica sobre os mesmos, causando assim, danos irreversíveis ao ambiente e reduzindo proporcionalmente a produtividade das culturas ali plantadas. A modificação da qualidade do solo está intimamente ligada às alterações no entorno da paisagem e, consequentemente, a qualidade da água dos cursos hídricos que recebem os sedimentos dos solos desestruturados.

O município de São Lourenço do Sul/RS já sofreu uma série de eventos de desastres naturais, tais como enxurradas, inundações e alagamentos desde o ano de 1932 (CEPED/RS, 2015), segundo dados disponibilizados pela Coordenadoria Municipal de Defesa Civil de São Lourenço do Sul. Conforme dados, pode-se citar que os anos de 1995 e 2011 foram os anos com eventos de inundação e enxurradas com Decreto de Situação de Emergência no município, e no ano de 2011 ocorreram sete mortes e 20.000 pessoas atingidas.

Um dos fatores diretamente correlacionados a esses eventos extremos é o uso excessivo e sem planejamento do solo - seja relacionado a áreas agrícolas ou a instalações irregulares por parte da população nas margens de cursos hídricos - gerando degradação dos recursos naturais existentes e, consequentemente, problemas ambientais associados, contribuindo para erosão local do solo. Segundo Costa et al. (2013), as erosões urbanas têm se tornado um dos problemas socioambientais mais estudados pelos cientistas de todas as áreas do conhecimento. Percebe-se, porém, uma crescente busca para o controle e o não surgimento de novos focos de erosão. Contudo, o estudo do uso inadequado de capacidade do solo é geralmente dispendioso e demanda tempo, por isso, a utilização de ferramentais que permitam analisar a utilização destes solos vem sendo cada vez mais usadas para identificar locais de esgotamento da parcela do solo e impactos ambientais negativos (MIGUEL, 2010).

O geoprocessamento pode ser definido como sendo o conjunto de tecnologias destinadas à coleta e tratamento de informações espaciais, assim como o desenvolvimento de novos sistemas e aplicações, com diferentes níveis de sofisticação (ROSA, 2013). O sensoriamento remoto é uma das ferramentas do geoprocessamento que, conforme Lima et al. (2017), utiliza sensores na obtenção de imagens e outros dados 
através da captação e registro da energia refletida ou emitida pela superfície da Terra. Para que ocorra a obtenção de dados, o alvo que está na superfície terrestre precisa captar e refletir a energia eletromagnética, proveniente do Sol, para que ocorra uma interação entre alvo e sensor (SANTOS, 2017).

Pode ocorrer a reflexão, absorção ou transmissão de energia radiante (em objetos com transparência) quando há interação da radiação com um objeto. Em geral, a parte absorvida é transformada em calor ou em algum outro tipo de energia e a parte refletida se espalha pelo espaço. A refletância, absortância e transmitância costumam ser expressas em percentagem ou por um número entre 0 e 1 (MOREIRA, 2001). Moraes (2002) exemplifica que os objetos interagem de maneira diferenciada espectralmente, pois apresentam diferentes propriedades físico-químicas e biológicas.

Estas diferentes interações é que possibilitam a distinção e o reconhecimento dos diversos objetos terrestres imageados remotamente, conhecida como assinatura espectral, devido à variação da porcentagem de energia refletida em cada comprimento de onda. No presente trabalho, para realizar a classificação das imagens RapidEye através do programa ENVI, buscou-se o auxílio da assinatura espectral da vegetação, pois a cobertura de vegetação, de acordo com Karaburun (2010), é o indicador biofísico mais importante para a erosão do solo. E o mesmo autor, ainda cita que a cobertura vegetal pode ser estimada usando índices de vegetação derivados de imagens de satélite.

Para tanto, utilizou-se o Índice de Vegetação por Diferença Normalizada ou NDVI (sigla de Normalized Difference Vegetation Index), uma vez que este permite discriminar assinaturas espectrais com base nas mudanças do bioma (SMIT, 2014). O NDVI é um elemento importante para o estudo de mudanças climáticas, utilizando a vegetação como índice de cálculo, atribuindo à área estudada um determinado valor que dependerá do estado em que se encontra essa vegetação (LOPES et al., 2010).

As imagens utilizadas no trabalho são de uma empresa alemã RapidEye AG que, em 2008, lançou um conjunto de cinco satélites com sensores capazes de adquirir imagens coloridas com resolução espacial de cinco metros (INPE, 2011). As imagens RapidEye possuem cinco bandas distintas, conforme Tabela 2, o que de acordo com Felix (2009) é o primeiro sistema orbital a incluir a banda Red-Edge, específica para o monitoramento da atividade fotossintética da vegetação, que mede variações nos tons, permitindo a separação de espécies e monitoramento da saúde da vegetação.

Sendo assim, o trabalho tem por objetivo classificar o uso atual das terras no município de São Lourenço do Sul/RS, através de imagens RapidEye do período de 2014/2015 com auxílio de técnicas de geoprocessamento, comparando este com o tipo de uso do solo proposto pela Embrapa Clima Temperado, identificando as áreas de incompatibilidade e possíveis surgimentos de impactos ambientais negativos, tendo em vista a classificação proposta pela Embrapa como a mais adequada.

\section{METODOLOGIA}

\section{Área de estudo}


O município de São Lourenço do Sul situa-se a uma distância aproximada de $195 \mathrm{~km}$ da capital do estado, Porto Alegre, e a 70 km do município de Pelotas. Os principais acessos viários para o município podem ser feitos pelas BR-116 e RS-265. Segundo dados do IBGE (2016) a área total do município é de, aproximadamente, $2036 \mathrm{~km}^{2}$ e possui uma população de 44.580 mil habitantes. A figura 1 identifica a localização da área de estudo.

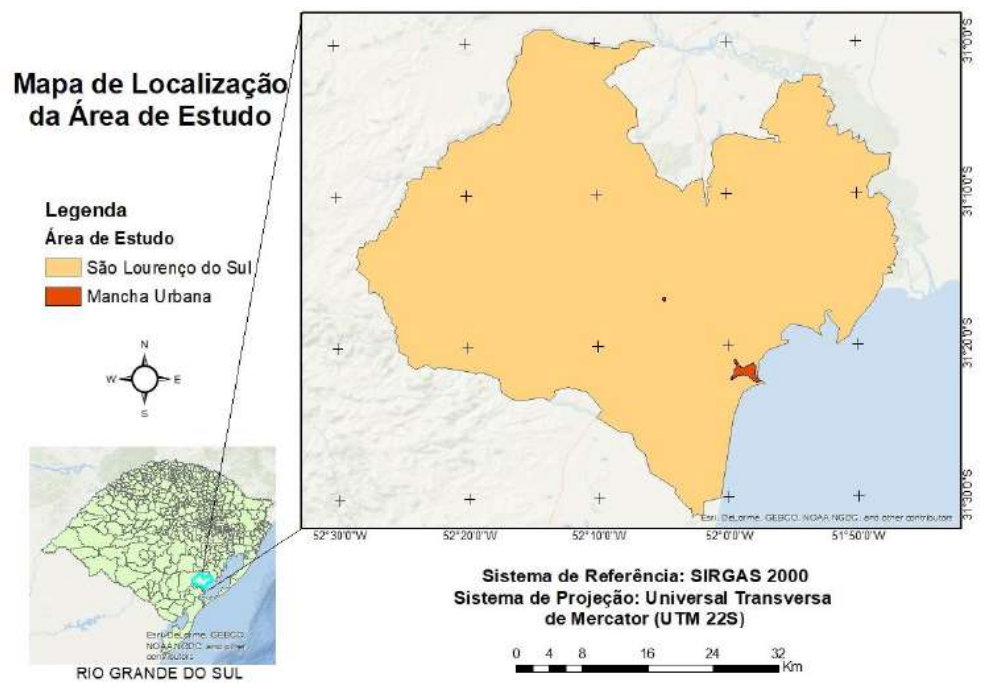

Figura 1: Mapa de localização.

\section{Classificação dos solos original}

Conforme proposto pela Embrapa (2013), os solos presentes no município de São Lourenço do Sul, em sua maioria, podem ser divididos em decorrência da forma de relevo existente. Onde se apresentam as maiores altitudes, referentes aos relevos de serra e colinas, predominam os argissolos que apresentam textura argilosa abaixo do horizonte $A$, sendo este geralmente arenoso. Podem ser distróficos, possuindo maior suscetibilidade a erosão, ou eutróficos, onde essa suscetibilidade torna-se reduzida por se apresentarem mais porosos (CUNHA et al., 2006).

Nas formas de relevo denominadas planícies predominam os planossolos, neossolos e gleissolos. Os planossolos apresentam segundo Cunha et al. (2006), processo de desargilização (perda de argila), sendo responsável pela predominância da textura arenosa no horizonte A destes solos. Possuem, conforme Almeida et al. (2011) permeabilidade lenta, por conta do adensamento (acúmulo nas camadas inferiores) de argila e, consequentemente, são solos suscetíveis a erosão, conforme figura 2.

Neossolos flúvicos são formados por sobreposição de camadas de sedimentos aluviais, apresentam baixa fertilidade natural, risco de inundação, além de suscetíveis a erosão (SILVA 2011). Os gleissolos são solos com horizonte superficial de coloração acinzentada até preta, hidromórficos (condições naturais de saturação por água) e com lençol freático elevado. Os gleissolos melânicos eutróficos possuem alta fertilidade e, pela proximidade a cursos hídricos tem suas áreas indicadas para preservação da mata ciliar (SANTOS, 2011).

Atrelado a classificação dos solos presentes no município de São Lourenço do Sul, Cunha et al. (2006) também propôs uma classificação para áreas próprias e impróprias para cultivo na região, totalizando oito 
classes diferentes, conforme tabela 1. Apesar de existirem classificações mais atualizadas para uso e cobertura da terra, como a proposta pelo IBGE (2016), esta não possui uma escala tão precisa quanto a proposta por Cunha et al. (2006) em parceria com a Embrapa (2013).

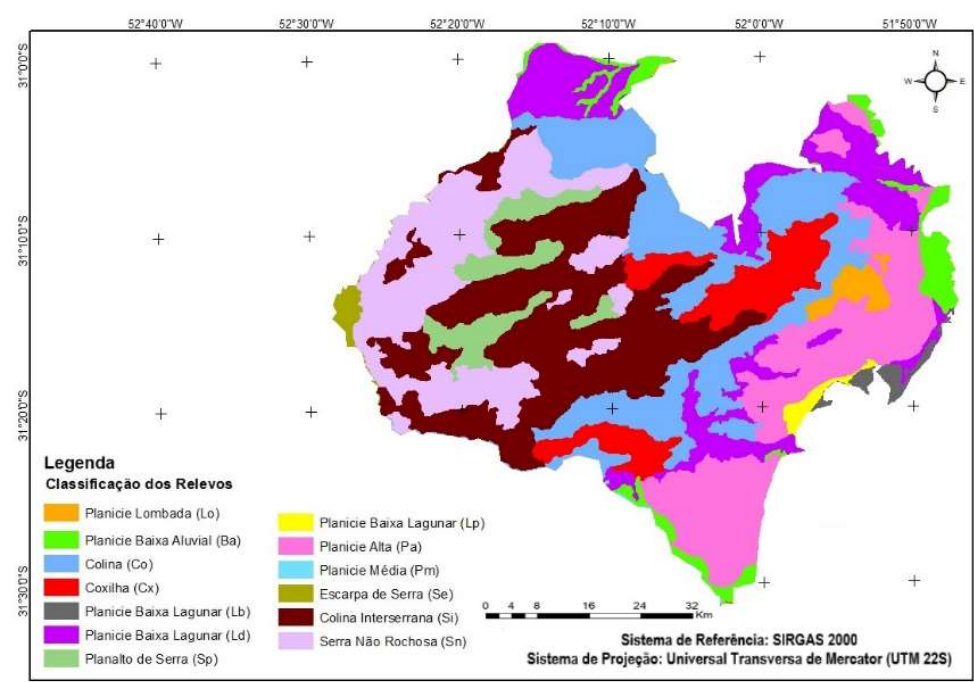

Figura 2: Classificação dos relevos.

Tabela 1: Classes para áreas próprias e impróprias para cultivo no município de São Lourenço do Sul.

\begin{tabular}{|l|l|l|}
\hline Classes & Características & Relevo correspondente \\
\hline IIsd & Solo profundo e úmido (permite cultivo) & Planície Lombada \\
\hline Illsd & Solo raso argiloso (permite cultivo) & Planície Alta e Média \\
\hline IIIse & Solo profundo argiloso (permite cultivo) & Colina Interserrana \\
\hline IVse & $\begin{array}{l}\text { Solo pouco profundo com susceptibilidade moderada de erosão (permite } \\
\text { cultivo moderado) }\end{array}$ & Serra não rochosa e Coxilha \\
\hline Vd & Solos aluviais inundados (não permite cultivo) & Planície Baixa Aluvial \\
\hline VIse & Solos rasos com susceptibilidade moderada de erosão (não permite cultivo) & Planalto de Serra e Colina \\
\hline VIIse & Solos rasos com susceptibilidade muito forte de erosão (não permite cultivo) & Escarpa de Serra \\
\hline VIIsc & Solo arenoso com forte falta de água (não permite cultivo) & $\begin{array}{l}\text { Planície Baixa Lagunar (Duna e Traço de } \\
\text { Praia) }\end{array}$ \\
\hline VIIIsd & $\begin{array}{l}\text { Solos inundados com limitação muito forte de drenagem e mecanização (não } \\
\text { permite cultivo) }\end{array}$ & Planície Baixa Lagunar (Banhado) \\
\hline
\end{tabular}

Fonte: Cunha et al. (2006).

Conforme a original classificação do uso da terra na área de estudo, percebe-se que das Classes I a IV não existem limitações da capacidade de uso do solo, entretanto das Classes V a VIII não se permite o uso na área agrícola, por apresentar características desfavoráveis como solos rasos, déficit hídrico e suscetibilidade a erosão.

\section{Dados Utilizados}

Os dados fornecidos pela Embrapa (2013) para solos encontram-se numa escala 1:50000 e foram gerados por Cunha et al. (2006), publicados no documento Solos e Terras do Planalto Sul-Rio-Grandense e Planícies Costeiras, no mesmo ano. Posteriormente, estes dados foram transpostos no formato de livro por Flores et al. (2009).

As imagens RapidEye foram obtidas através do Geo Catalogo do Ministério do Meio Ambiente (MMA) e são de uso exclusivo para instituições públicas. O conjunto de cenas orbitais utilizadas para compor o 
município de São Lourenço do Sul datam do período de 2014/2015, estão na escala 1:25000 e seguem identificadas na tabela 2 (estas possuem todos os direitos reservados).

Tabela 2: Imagens RapidEye do município de São Lourenço do Sul.

\begin{tabular}{|l|l|l|}
\hline Sensor & Nome da Imagem & Data da Imagem \\
\hline RapidEye & Órbita 2224510 & $09 / 11 / 2014$ \\
\hline RapidEye & Órbita 2224609 & $22 / 10 / 2014$ \\
\hline RapidEye & Órbita 2224610 & $05 / 01 / 2014$ \\
\hline RapidEye & Órbita 2224611 & $29 / 08 / 2014$ \\
\hline RapidEye & Órbita 2224709 & $05 / 07 / 2015$ \\
\hline RapidEye & Órbita 2224710 & $29 / 11 / 2014$ \\
\hline RapidEye & Órbita 2224711 & $09 / 11 / 2014$ \\
\hline RapidEye & Órbita 2224810 & $28 / 09 / 2014$ \\
\hline
\end{tabular}

Fonte: RapidEye (2012).

Todos os dados disponibilizados, inicialmente, estavam no formato matricial e, foram convertidos para dados vetoriais, de extensão Shapefile. Indiferente do sistema de referência inicial, todos os dados foram alocados no banco de dados e normatizados em um sistema de referência único, SIRGAS 2000 (Sistema de Referência Geocêntrico para as Américas - 2000), projetados em UTM (Universal Transversa de Mercator) no fuso $22 \mathrm{~S}$. Os softwares utilizados foram QGIS (versão 2.18) para realização das análises espaciais, para o processo de classificação utilizou-se o ENVI (versão 4.7) e o ARCGIS, para confecção dos mapas temáticos.

\section{Classificação de Imagens}

Para imagens RapidEye, as bandas 3 (vermelho) e 4 (infravermelho próximo) atuam nas faixas de 630 a $690 \mathrm{~nm}$ para a vermelha e de 760 a $880 \mathrm{~nm}$ para a infravermelha. A medição é feita através da equação 1 (DEERING et al., 1975; FERREIRA; MAGALHÃES, 2015; GAMARRA et al., 2016).

$$
\mathrm{NDVI}=\frac{(\mathrm{NIR}-\mathrm{RED})}{(\mathrm{NIR}+\mathrm{RED})}
$$

Onde:

NIR: resposta espectral do pixel na banda do infravermelho próximo RED: resposta espectral do pixel na banda do visível (vermelho)

O cálculo resulta em um índice que varia entre -1 e 1 . Na prática, o índice representa a presença de vegetação onde, quanto maior seu valor, maior será a quantidade vegetativa do local (sendo assim, maior será a refletância e mais próxima da cor branca a imagem). Valores negativos ou próximos a zero indicam áreas de água, ou solo nu, onde existe pouca atividade clorofiliana e, consequentemente, baixa quantidade de vegetação (GURGEL, 2003), logo, mais escura a representação na imagem.

Para a posterior classificação de imagens no programa ENVI, optou-se pela classificação digital supervisionada pelo método de máxima verossimilhança (MaxVer) - escolhida por ser a mais utilizada em objetos de estudo para classificação - obtida em função do conhecimento prévio de padrões espectrais das áreas amostrais (FARIA et al., 2013; MENESES et al., 2012). Isso permitiu a seleção de áreas confiáveis, de forma manual, definindo-se que o algoritmo classificador operasse com base na probabilidade de um dado pixel pertencer a uma classe específica (INPE, 2011), realizada em função dos cinco temas de interesse.

Sendo assim, nas imagens RapidEye disponíveis, foram definidas as seguintes classes: (a) água, (b) ocupação urbana, (c) vegetação, (d) cultivos/pastagem; e (e) solo exposto. Cada classe necessitou de 20 
amostras de classificação, ao longo de toda imagem, e 5 amostras para verificação (tidas como reais). Logo, como são cinco classes, foram 100 amostras de classificação e 25 amostras de verificação.

Cabe destacar que a qualidade das classificações realizadas é definida pela matriz de confusão, ou matriz de erros, que é obtida após a comparação dos pontos de verificação com os referentes a classificação supervisionada. Sendo assim, a partir do cruzamento destas informações pode-se calcular a exatidão global e o índice Kappa (HENTZ et al., 2015). Busca-se que, os valores obtidos na exatidão global sejam altos, pois a quantidade de pixels classificados corretamente está diretamente relacionada ao seu valor, sendo assim, quanto maior o valor da exatidão global, maior o índice de acurácia da análise (CECCONELLO, 2017; HENTZ et al., 2015; NASCIMENTO et al., 2016). Em relação ao índice Kappa, proposto por Landis et al. (1977), este varia de 0 a 1 e segue expresso conforme a tabela 3.

Tabela 3: Classificação do coeficiente Kappa.

\begin{tabular}{|l|l|}
\hline Coeficiente Kappa & Classificação \\
\hline$<0,00$ & Ruim \\
\hline $0,00-0,20$ & Fraco \\
\hline $0,21-0,40$ & Razoável \\
\hline $0,41-0,60$ & Boa \\
\hline $0,61-0,80$ & Muito Boa \\
\hline $0,81-1,00$ & Excelente \\
\hline
\end{tabular}
Fonte: Landis et al. (1977).

De acordo com Landis et al. (1977) o coeficiente Kappa igual ou inferior a zero determina uma classificação como ruim, devendo esta ser refeita. Já, índices próximos a um, identificam uma classificação como excelente, com dados estimados de forma precisa, que representam a verdade de campo. Após o resultado do coeficiente Kappa, foi realizada uma análise virtual para verificar se a classificação vai possibilitar um estudo representativo da região.

\section{RESULTADOS E DISCUSSÃO}

Através do auxílio das imagens geradas por NDVI, conseguiu-se maior precisão, na coleta amostral, para identificação das classes propostas para estudo (Classe I - Solo exposto; Classe II - Cultivos/Pastagens; Classe III - Vegetação nativa; Classe IV - Área urbana e Classe V - Água). Na figura 3 apresentam-se o mapa do município de estudo com as imagens geradas por NDVI. Após finalizada a coleta das amostras, com auxílio das imagens NDVI, utilizou-se o método da verossimilhança (MaxVer) para classificação supervisionada.

Na pós-classificação, gerou-se a matriz de confusão para determinar a qualidade da classificação supervisionada realizada. Nesta, pode-se avaliar os resultados estimados, identificando-se com que frequência o modelo é previsto com precisão, através da quantidade e dos percentuais existentes em cada célula desta matriz.

$\mathrm{Na}$ tabela 4 segue expressa a matriz de confusão, com os valores de exatidão global e índice Kappa gerados para o quadrante 2224610, através da classificação supervisionada para o município de São Lourenço do Sul. As demais matrizes geradas para a totalidade de imagens analisadas seguem agrupadas em uma única tabela (tabela 4), devido ao limite de páginas. 


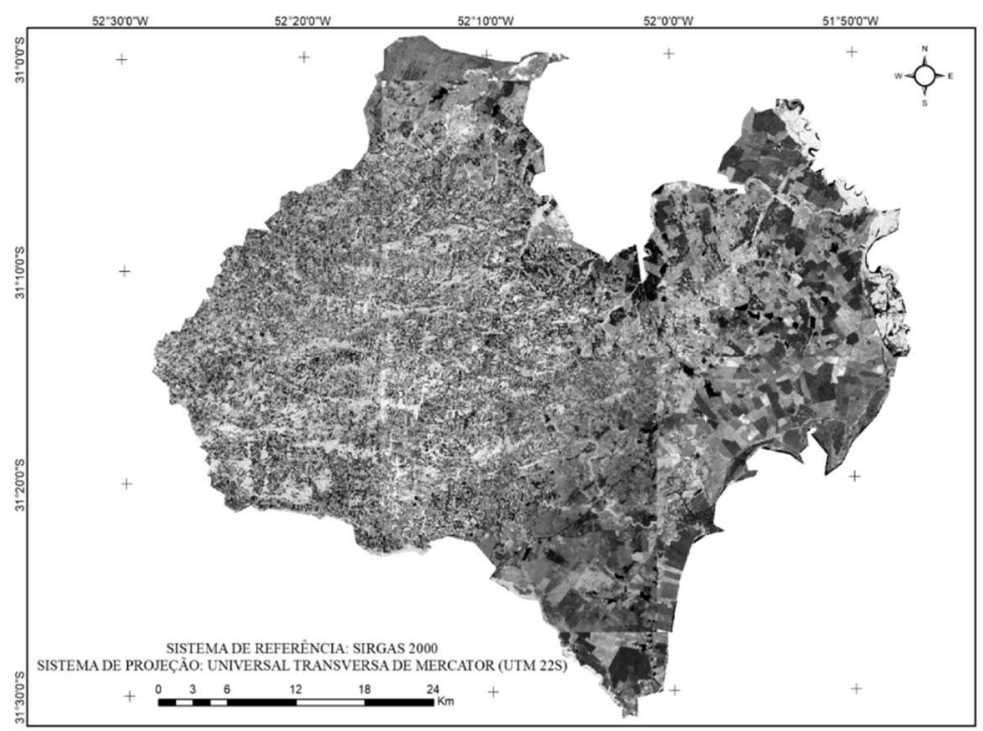

Figura 3: Índice de Vegetação por Diferença Normalizada para São Lourenço do Sul.

Tabela 4: Matriz de confusão para quadrante 2224610.

\begin{tabular}{|l|l|l|l|l|}
\hline $\begin{array}{l}\text { Exatidão Global = (4495/4526) 99,3\% } \\
\text { Índice Kappa = 0,99 }\end{array}$ & Água & Cultivos \\
\hline Classes & Solo Exposto & Vegetação & Án \\
\hline Solo Exposto & 100 & 0,00 & 0,00 & 0,81 \\
\hline Vegetação & 0,00 & 99,85 & 0,00 & 0,00 \\
\hline Água & 0,00 & 0,15 & 99,75 & 1,26 \\
\hline Cultivos & 0,00 & 0,00 & 0,25 & 97,93 \\
\hline Total & 100 & 100 & 100 & 100 \\
\hline
\end{tabular}

Analisando-se a matriz de confusão percebe-se que do total de amostras digitais coletadas (4526), 4495 estão correlacionadas corretamente. Para a órbita 2224610, nota-se que do total de pixels classificados para classe vegetação apenas 0,15 \% não foram enquadrados na classe correspondente, sendo classificados como água. Na classe água, da totalidade de pixels amostrados apenas $0,25 \%$ apresentou confusão com a classe cultivos.

A classe que apresentou maior índice de confusão foi o cultivo/pastagem. Nela, 0,81 \% dos pixels analisados foi confundido com solo exposto e 1,26 \% com a classe água. Entretanto, na classe solo exposto a porcentagem de erro foi nula, onde todos os pixels foram amostrados corretamente. Pode-se perceber que o valor obtido para índice Kappa foi igual a 0,99, identificando que a qualidade da classificação de imagem foi excelente. A exatidão global também se apresentou satisfatória, pois mais de $99 \%$ dos pixels foram classificados corretamente. Posto isso, a classificação supervisionada para esta órbita encontra-se o mais próximo possível do cenário real.

Tabela 5: Índice de acurácia para a totalidade de imagens classificadas.

\begin{tabular}{|c|c|c|c|c|c|c|c|c|}
\hline \multirow[t]{2}{*}{ Índice de Acurácia } & \multirow{2}{*}{$\begin{array}{l}\text { Órbita } 222 \\
4510\end{array}$} & \\
\hline & & 4609 & 4610 & 4611 & 4709 & 4710 & 4711 & 4810 \\
\hline Exatidão Global (\%) & 93,2 & 94,7 & 99,3 & 93,7 & 96,4 & 97,7 & 99,6 & 100 \\
\hline Índice Kappa & 0,91 & 0,93 & 0,99 & 0,91 & 0,94 & 0,97 & 0,995 & 1,0 \\
\hline
\end{tabular}

$\mathrm{Na}$ tabela 5 apresenta-se o percentual de exatidão global e do coeficiente Kappa para todas as imagens, através da classificação supervisionada pelo método da verossimilhança. Conforme análise da matriz de confusão para o município de São Lourenço do Sul, observa-se que todas as classificações possuem 
exatidão global superior a 93\% e índice Kappa superior a 0,9, demonstrando a eficácia do método de classificação.

A figura 4 exemplifica a totalidade do município de São Lourenço do Sul através da classificação supervisionada. Por meio da classificação supervisionada gerada para a totalidade do município percebe-se que há um predomínio maior de vegetação nativa na porção leste. Já, onde há predomínio de cultivos ou pastagem, consequentemente, ressalta-se maior quantidade de solo exposto. Comparando com a classificação de uso do solo proposta por Cunha et. al. (2006) e disponibilizada pela Embrapa (2013), percebese que alguns solos que são classificados como favoráveis ao cultivo não estão sendo utilizados para este fim, sendo o caso da serra não rochosa e coxilha. Em contrapartida, solos suscetíveis a erosão e com baixa disponibilidade hídrica, como as colinas, estão sendo utilizados para cultivo. Fica evidente, também, que quanto mais próximo da mancha urbana, maior a tendência a existir cultivos e/ou pastagem, por conta do desenvolvimento da área.

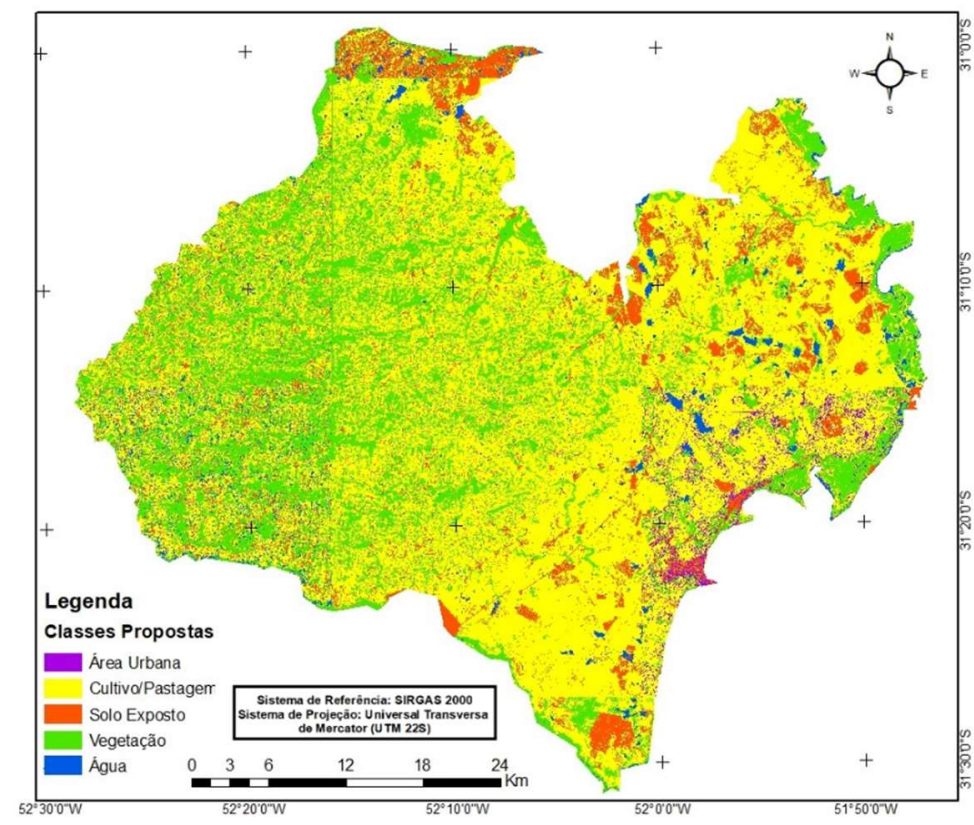

Figura 4: Classes de uso da terra.

Entretanto, alguns usos originais do solo estão sendo respeitados. Observa-se que os solos relacionados a qualquer forma de planície baixa lagunar, seja ela duna, traço de praia ou banhado, não são utilizados para cultivo, conforme estipulado na capacidade original de uso. Também se percebe que, solos que possuem capacidade para receber culturas estão sendo utilizados para este fim, sendo o caso dos tipos de solo relacionados as formas de relevo de planície alta.

\section{CONCLUSÕES}

Apesar do município de São Lourenço do Sul possuir uma classificação para o seu uso do solo, constatou-se que essa capacidade não caracteriza completamente o cenário real, não havendo cumprimento por parte dos moradores nem fiscalização do poder público. Através da classificação supervisionada MaxVer pode-se definir o uso do solo para o município, referente aos anos de 2014/2015 e, baseando-se nele, definir 
o uso do solo atual. Observando imagens de outros sensores recentes, percebe-se que a classificação do uso do solo referente a 2014/2015 ainda é representativa do uso atual no município. Sendo assim, com o auxílio das imagens de satélite foi realizada a caracterização do uso do solo com alto índice de precisão, representando a verdade em campo.

Uma das medidas necessárias para redução do alto grau erosivo no município, através de incentivos e fiscalização do poder público, é a criação de planos e programas que facilitem a identificação da área ideal a ser cultivada, bem como as corretas técnicas de plantio e manejo a serem utilizadas por parte do agricultor, mitigando as perdas e conservando o solo. Entretanto, o geoprocessamento de imagens torna-se uma ferramenta suporte, de grande importância, para as tomadas de decisão frente alternativas de correto manejo e conservação do solo, bem como a implantação de práticas conservacionistas que exerçam resultados positivos no controle e redução das perdas de solo.

\section{REFERÊNCIAS}

ALMEIDA, E. P. C.; ZARONI, M. J.; SANTOS, H. G.. Planossolos Háplicos. Agência Embrapa de Informação Tecnológica, 2011.

CECCONELLO, S. T.. Análise ambiental dos processos dinâmicos do uso e cobertura da terra sobre as áreas de preservação permanente no município de pelotas entre os anos de 1985 e 2015. Dissertação (Mestrado em Desenvolvimento Territorial e Sistemas Agroindustriais) Universidade Federal de Pelotas, Pelotas, 2017.

CEPED/RS. Centro Universitário de Estudos e Pesquisas Sobre Desastres. Mapeamento de vulnerabilidade de áreas suscetíveis a deslizamentos e inundações - São Lourenço do Sul/RS. Relatório. Porto Alegre, 2015.

COSTA, K. V. M; BARRETO, A. C.; FONTENELE, S. B.; MENDONÇA, L. A. R.. Estimativa de perda de solo distribuída em uma bacia hidrográfica de pequeno porte através de técnicas de geoprocessamento. In: SIMPÓSIO BRASILEIRO DE SENSORIAMENTO REMOTO - SBSR, 16. Anais. Foz do Iguaçu: INPE, 2013.

CUNHA, N. G.; SILVEIRA, J. C.; SEVERO, C. R. S.. Solos e Terras do Planalto Sul-Rio-Grandense e Planícies Costeiras. Circular Técnica 55. Ministério da Agricultura, Pecuária e Abastecimento. Pelotas: Embrapa Clima Temperado, 2006.

DEERING, D. W.; ROUSE, J. W.; HAAS, R. H.; SCHELL, J. A.. Measuring 'forage production' of grazing units from Landsat MSS data. In: International Symposium on Remoting Sensing of Environment, 10. Anais. Ann Arbor: ERIM, 1975. v.2, p.1169-1178.

EMBRAPA. Centro Nacional de Pesquisa de Solos. Sistema brasileiro de Classificação de solos. Brasília: Embrapa Produção de informação; Rio de Janeiro: Embrapa Solos, 2013.

FARIA, M. M.; FILHO, E. I. F.. Avaliação dos algoritmos SVM e Maxver para a classificação de sistemas florestais monodominantes de candeia (Eremanthus sp.). In: SIMPÓSIO BRASILEIRO DE SENSORIAMENTO REMOTO SBSR, 16. Anais. Foz do Iguaçu: INPE, 2013.
FELIX, I. M.; KAZMIERCZAK, M. L.; ESPINDOLA, G. M.. RapidEye: a nova geração de satélite de Observação da Terra. In: SIMPÓSIO BRASILEIRO DE SENSORIAMENTO REMOTO - SBSR, 14. Anais. São José dos Campos: INPE, 2009. p.7619-7622.

FERREIRA, V. O.; MAGALHÃES, M. V. P.. Aplicação do Índice da Vegetação por Diferença Normalizada (NDVI) à Análise Multitemporal da Dinâmica de Áreas Agrícolas no Alto Curso da Bacia do Rio Uberabinha, Caderno de Geografia, v.25, n.44, 2015.

FLORES, C. A.; FILIPPINI-ALBA, J. M.; WREGE, M. S.. Zoneamento agroclimático do eucalipto para o Estado do Rio Grande do Sul e edafoclimático na região do Corede Sul - RS. Pelotas: Embrapa Clima Temperado, 2009.

GAMARRA, R. M.; TEIXEIRA-GAMARRA, M. C.; CARRIJO, M. G. G.; PARANHOS FILHO, A. C.. Uso do NDVI na análise da estrutura da vegetação e efetividade da proteção de unidade de conservação no cerrado. Ra'EGa, Curitiba, v.37, p.307-332, 2016.

GURGEL, R. G. A.. Principais variedades e espécies de gramas. In: SIMPÓSIO SOBRE GRAMADOS. Anais. Botucatu: Universidade Estadual Paulista, 2003.

HENTZ, A. M. K.; CORTE, A. P. D.; BLUM, C. T.; SANQUETTA, C. R.. Técnicas orientadas ao objeto para levantamento da fragmentação florestal na sub-bacia Alto Iguaçu, Paraná. Revista Geociências. São Paulo, v.34, n.4, p.883-896, 2015.

IBGE. Instituto Brasileiro de Geografia e Estatística. Censo demográfico 2016. Famílias e domicílios. Resultados da amostra. 2016.

INPE. Manuais: tutorial de geoprocessamento SPRING. 2011.

KARABURUN, A.. Estimation of C factor for soil erosion modeling using NDVI in Buyukcekmece watershed. Ozean Journal of applied sciences, v.3, n.1, p.77-85, 2010. 
LANDIS, J. R.; KOCH, G. G.. The Measurement of Observer Agreement for Categorical Data. Biometrics, v.33, n.1, p.159-174, 1977.

LOPES, A. S.; SILVA, H. P.; ARAUJO, I. R.; ALENCAR, B. P. B.; MELO, A. L.. Utilização de imagens de satélites e dados meteorológicos visando o monitoramento de mudanças climáticas. In: SIMPÓSIO BRASILEIRO DE CIÊNCIAS GEODÉSICAS E TECNOLOGIAS DA GEOINFORMAÇÃO, 3. Anais. Recife, 2010. p.1-4.

LIMA, D.; CARVALHO, D. A.; MORAIS, R. J.; GONÇALVES, T. V.; PRADO, V. H. M.. Levantamento cienciométrico do uso de sensoriamento remoto nas análises que envolvem os impactos ambientais na vegetação brasileira. In: CONGRESSO DE ENSINO, PESQUISA E EXTENSÃO DA UEG (CEPE). Anais. 2017.

MELO, R. O.; CANTALICE, J. R. B.; ARAUJO, A. M.; CUNHA FILHO, M.. Produção de sedimento suspenso de uma típica bacia hidrográfica semiárida. In: ENCONTRO NACIONAL DE ENGENHARIA DE SEDIMENTOS, 8. Anais. Gravatá, 2008.

MENESES, P. R.; ALMEIDA, T.. Introdução ao processamento de imagens de sensoriamento remoto. Brasília: UNB, 2012.

MIGUEL, P.. Caracterização pedológica, uso da terra e modelagem da perda de solo em áreas de encosta do rebordo do planalto do RS. Dissertação (Mestrado em Ciência do Solo) - Universidade Federal de Santa Maria, Santa Maria, 2010.
MORAES, E.. Fundamentos de Sensoriamento Remoto. São José dos Campos: INPE, 2002.

MOREIRA, M. A.. Fundamentos de Sensoriamento Remoto e Metodologias de Aplicação. 1 ed. São José dos Campos, 2001.

NASCIMENTO, I. S.; CRUZ, C. B. M. C.; NEVES, S. M. A. S.; GALVANIN, E. A. S.. Avaliação da exatidão dos classificadores MaxVer e iso cluster do software Arcgis for desktop, com uso de imagem LANDSAT 8 do município de Cáceres/MT. Revista Continente. Rio de Janeiro, v.5, n.8, p.48-62, 2016.

ROSA, R.. Introdução ao Geoprocessamento. Universidade Federal de Uberlândia, Instituto de Geografia. 2013.

SANTOS, H. G.; ZARONI, M. J.. Gleissolos: Definições e Características em Geral. Agência Embrapa de Informação Tecnológica. 2011.

SILVA, M. S. L.; NETO, M. B. O.. Neossolos Flúvicos. Agência Embrapa de Informação Tecnológica, 2011.

SMIT, S.. Observation of the change in vegetation density in degraded areas, of the Baviaanskloof catchment: Based on remote sensing techniques that estimate the relation between vegetation density and NDVI (Normalized Difference Vegetation Index). Amsterdam: University of Applied Science Van Hall Larenstein. 2014. 